\title{
Polymer-clay nanocomposites obtained by solution polymerization of vinyl benzyl triammonium chloride in the presence of advanced functionalized clay
}

\author{
RALUCA IANCHIS $^{\mathrm{a}}$, DAN DONESCU ${ }^{\mathrm{a}}$, LUDMILA OTILIA CINTEZA ${ }^{\mathrm{b}}$, \\ VIOLETA PURCAR $^{\mathrm{a}, *}$, CRISTINA LAVINIA NISTOR ${ }^{\mathrm{a}}$, CRITIAN PETCU $^{\mathrm{a}}$, \\ CRISTIAN ANDI NICOLAE ${ }^{\mathrm{a}}$, RALUCA GABOR ${ }^{\mathrm{a}}$ and SILVIU PREDA ${ }^{\mathrm{c}}$ \\ ${ }^{a}$ National Research and Development Institute for Chemistry and Petrochemistry - ICECHIM Spl. \\ Independentei 202, 6th district,, 060021, Bucharest, Romania \\ ${ }^{b}$ Faculty of Chemistry, University of Bucharest, M Kogalniceanu, 5th District, 70709, Bucharest, Romania \\ 'Institute of Physical Chemistry 'Ilie Murgulescu', Romanian Academy, Spl. Independentei 202, 6th District, \\ 060021, Bucharest, Romania \\ e-mail: violetapurcar@yahoo.com
}

MS received 25 October 2013; revised 7 January 2014; accepted 11 January 2014

\begin{abstract}
Polymer-clay nanocomposites were synthesized by solution polymerization method using advanced functionalized clay and vinyl benzyl trimethyl ammonium chloride as monomer. First stage consisted in the silylation of a commercial organo-modified clay-Cl $20 \mathrm{~A}$ using alkoxysilanes with different chain lengths. In the second step, the synthesis and characterization of polymer-nanocomposites were followed. To evaluate the clay functionalization process as well as the final polymer-clay products, thermogravimetric, X-ray diffraction, dynamic light scattering, Fourier transform infrared spectroscopy and three test liquid contact angles analyses were used. The loss of ammonium ions from commercial clay, the grafting degree, the lengths and the nature of alkyl chain influence the dispersion of the advanced modified clay into the polymer solution and, furthermore, the properties of the final polymer-clay nanocomposite film.
\end{abstract}

Keywords. Layered silicates; silanes; poly (vinyl benzyl trimethyl ammonium chloride); nanocomposites.

\section{Introduction}

Clay minerals can be found all over the world. ${ }^{1}$ Clay minerals have unique ion exchange, swelling and intercalation capacities. This makes them suitable in a wide range of application as polymer-clay nanocomposites, rheological modifier in paints, inks, greases, absorbent for toxic gases, drug delivery systems. ${ }^{2-8}$ The most commonly used clay in the synthesis of polymer nanocomposites is montmorillonite. Montmorillonite is hydrophilic while most polymers are hydrophobic. In order to obtain polymer-clay nanocomposites, one of the two has to be modified., ${ }^{4-11}$ Organo-clays can also exhibit hydrophilic-hydrophobic behaviour due to interlayer modification with quaternary ammonium salts or covalent bonding with silanes at the $\mathrm{OH}$ edges of the clay. There are recent studies that showed the successful modification of clays with alkoxysilanes and their interaction with different polymers., ${ }^{411-13}$

On the other hand, amphiphilic polymers have been of great interest because of the possibility to

*For correspondence explore their hydrophilic-hydrophobic behaviour in many applications like ion-exchange membranes, in fuel cells, advanced molecular engineering applications, mineral processing, water treatment, petroleum recovery and paper making industries. ${ }^{14-16}$ Quaternary ammonium salt polymers are the most important and extensively used cationic polymers because they are very effective against a large spectrum of microorganism such as bacteria, algae, fungi. ${ }^{15,17}$ Poly vinyl benzyl trimethyl ammonium chloride was reported to be the most chemically stable polymer among poly trialkyl ammonium salts. ${ }^{16}$

In this study, our goal was to synthesize polymer-clay nanocomposites using both, an amphliphilic monomer and commercial organophilic clay (already modified with quaternary ammonium salts). First stage consists of the functionalization of the commercial clay by edge covalent bonding with different monofunctional alkoxysilanes followed by solution polymerization of vinyl benzyl trimethyl ammonium chloride in the presence of the modified clays. To the best of our knowledge, this system was not studied before and turns out to be very challenging because of the combined dual 
nature of the amphiphilic polymer and advanced functionalized clay. Furthermore, these kinds of materials are suitable for application as ion selective membranes or film packaging. ${ }^{9,18}$

\section{Experimental}

\subsection{Materials and methods}

Commercial organo-clay (Cloisite 20A; $95 \mathrm{meg} / 100 \mathrm{~g}$ ) modified with dimethyl dihydrogenated tallow ammonium salt was purchased from Southern Clay Products Inc. Dichloromethane (DCM) from Chimreactiv was used without further treatment. The alkoxysilanes (trimethyl ethoxysilane, phenyl dimethylethoxysilane and octadecyl dimethylmethoxysilane), Vinyl benzyl trimethyl ammonium chloride (VBTAC) and 2, 2'-Azobis(2-methylpropionamidine) dihydrochloride (AIBA) (Aldrich) were used as received. Distilled water was used as dispersion media.

\subsection{Silylation of $\mathrm{Cl} 20 \mathrm{~A}$}

Dried Cl20A (4 g) and $250 \mathrm{ml} \mathrm{CH}{ }_{2} \mathrm{Cl}_{2}$ were introduced in a three-neck round bottom flask. The mixture was sonicated using a tip sonicator for $10 \mathrm{~min}$ on an ice bath. Then, was the magnetically stirred (300 rpm) and kept under purified nitrogen gas for $30 \mathrm{~min}$. The alkoxysilanes were added drop-wise. Then, the reaction mixture was heated to $40^{\circ} \mathrm{C}$ and refluxed for $24 \mathrm{~h}$. The reaction product was centrifuged and washed with $300 \mathrm{ml}$ $\mathrm{CH}_{2} \mathrm{Cl}_{2}$. The final product was dried in a vacuum oven at $60^{\circ} \mathrm{C}$ for $12 \mathrm{~h}$.

\subsection{VBTAC polymerization}

The polymer composites were obtained by using a sealed recipient, coupled with a thermostat bath under magnetic stirring. In the first stage, $4 \mathrm{~g}$ monomer (vinyl benzyl trimethyl ammonium chloride) was dissolved in $100 \mathrm{ml}$ water. Clay $(0.5 \mathrm{~g})$ was added and the solution was sonicated for $15 \mathrm{~min}$. The temperature was raised to $65^{\circ} \mathrm{C}$. The polymerization was initiated by adding a solution of $0.3 \mathrm{~g}$ AIBA. After $5 \mathrm{~h}$ of polymerization, the solution was cooled to room temperature. The final solutions were analysed through DLS method for size measurements. Small amounts of solution were deposed on a polyethylene foil for water evaporation, at room temperature for several days, in order to obtain hybrid films. The resulted materials were analysed through FTIR, TGA, XRD and contact angle.

\subsection{Measurements}

Particles hydrodynamic diameters and Zeta potential were determined by Dynamic Light Scattering (DLS) with Zetasizer Nano ZS, ZEN3600, produced by Malvern International Ltd.

The final products resulted after water evaporation, were analysed by FTIR. FTIR spectra were recorded in ATR mode, on a FTIR-Tensor 30 BRUCKER spectrometer, in the range of $400-4000 \mathrm{~cm}^{-1}$.

XRD analyses were performed using a RIGAKU Ultima IV Instrument with Parallel Beam geometry and Ultima IV In-plane Goniometer at $40 \mathrm{kV} / 30 \mathrm{~mA}(\mathrm{Cu}$ $\mathrm{Ka}$ ), in $2 \theta$ range: $1-30$ and 5_ scanning speed.

TGA analyses were performed with a TGA Q5000 instrument. The samples were heated, in nitrogen atmosphere $100 \mathrm{ml} / \mathrm{min}$ with a rate of $20^{\circ} \mathrm{C} / \mathrm{min}$.

The wettability of the functionalized clays as well as the polymer-clay hybrid films was determined by contact angle measurements.

The contact angle measurements on the functionalized clays were performed on clay compacted disks using the FTIR press at $15 \mathrm{MPa}$. Distilled water was used as reference liquid.

Contact angle measurements were also performed on the hybrid films. In this case, the three test liquid contact angle was measured. The films were prepared by casting the polymeric latex onto glass slides and drying at atmospheric pressure. The samples obtained were stored in a desiccator until ready for use. Static contact angle measurements were carried out using a DataPhysics instrument OCA 20 and computation of surface energy from the contact angle values was performed using the instrument software. For the three test liquids, the equilibrium contact angle was measured using the sessile-drop method, at room temperature. The volume of the liquid droplets was $5 \mu \mathrm{l}$ and the image of the drop profile was recorded during the first 15-20 s to avoid the dissolution of some chemical species from the film surface into the tested liquid. The value of the contact angle was determined as average value, on the basis of five values recorded for droplets placed in different region of the polymeric hybrid film. Since the polymeric material is water soluble and the organo-clays used exhibit various reactive organic moieties the reference liquids were selected as follows: ethylene glycol, glycerol and 1-bromonaphtalene, each of them with known surface free-energy parameters (data from OCA software database).

The surface energy of the material, and its dispersive and polar components were determined by using the Lifshitz-van der Waals model ${ }^{19}$ considered as the most suitable to describe the influence of the 


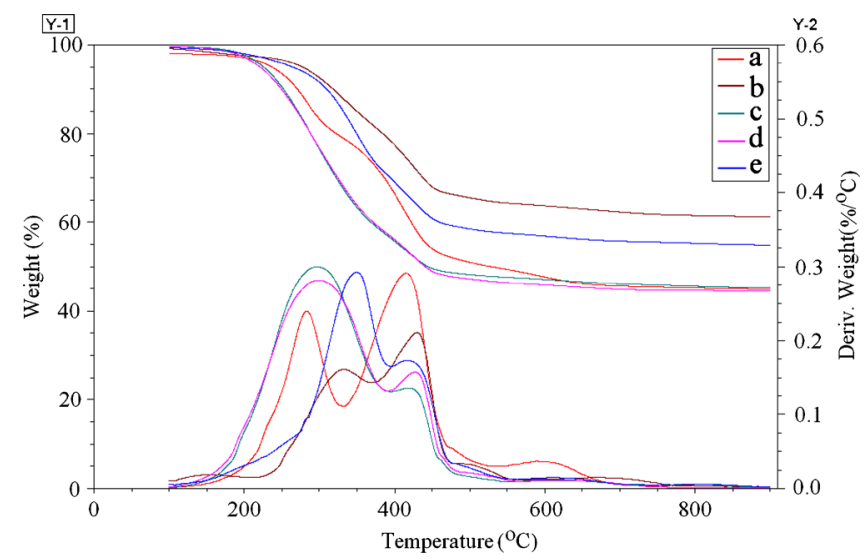

Figure 1. TGA-DTG curves obtained for $\mathrm{Cl} 20 \mathrm{~A}, \mathrm{Cl} 20 \mathrm{~A}-$ DCM and $\mathrm{Cl}$ 20A silylated derivatives (a, Cl 20A; b, Cl20ADCM; c, Cl 20AMe; d, Cl 20APh; e, Cl 20AC18).

organo-modified nanoclays on the properties of the polar polymer film.

\section{Results and discussion}

\subsection{Characterization of functionalized clay}

The first information about the functionalization of the organo-modified clay $\mathrm{Cl} 20 \mathrm{~A}$ has resulted from TGA analyses (figure 1). Two thermal degradation transitions were observed for $\mathrm{Cl} 20 \mathrm{~A}$, as follows: $100-550^{\circ} \mathrm{C}$ - the olefine and amine decomposition; $500-900^{\circ} \mathrm{C}$ - weight loss associated with the structural hydroxyl water. $^{12,20-22}$ The same degradation steps were evidenced for the silylated clays, but with major modifications especially in the range $200-550^{\circ} \mathrm{C}$.

Compared with $\mathrm{Cl} 20 \mathrm{~A}$, a greater weight loss for the silylated samples in the range of $100-550^{\circ} \mathrm{C}$ should be registered corresponding to the contribution of the organic part, respectively to the grafted silane chains. Due to the loss of ammonium salts which occur in the functionalization process ${ }^{22}$ a lower weight loss was obtained for the silylated samples than for $\mathrm{Cl} 20 \mathrm{~A}$. Therefore, a 'blind' sample was also prepared, without alkoxysilane, using simply $\mathrm{Cl} 20 \mathrm{~A}$ and DCM. The derivative thermograms obtained for $\mathrm{Cl} 20 \mathrm{~A}$ revealed a maximum peak at $415^{\circ} \mathrm{C}$ with a shoulder at $280^{\circ} \mathrm{C}$.

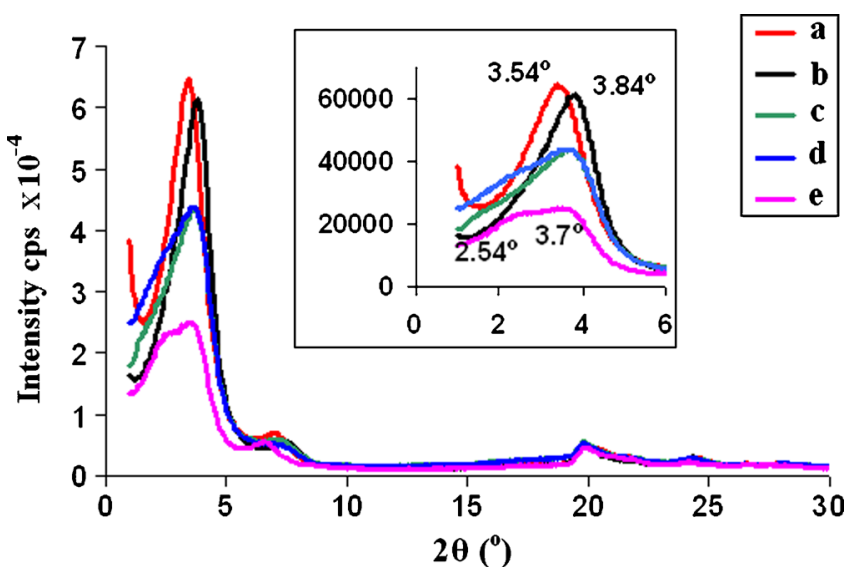

Figure 2. XRD patterns of $\mathrm{Cl} 20 \mathrm{~A}, \mathrm{Cl} 20 \mathrm{~A}-\mathrm{DCM}$ and $\mathrm{Cl}$ 20A silylated derivatives (a, Cl 20A; b, Cl20A-DCM; c, Cl 20AMe; d, Cl 20APh; e, Cl 20AC18).

DTG's of the 'blind' sample showed a decrease in peak intensity due to quaternary ammonium salt washing with $\mathrm{CH}_{2} \mathrm{Cl}_{2}$. For the silylated samples (Me and $\mathrm{Ph}$ ), the maximum peak was observed around $295^{\circ} \mathrm{C}$ with a shoulder around $420^{\circ} \mathrm{C}$ while for $\mathrm{Cl} 20 \mathrm{~A}-\mathrm{C} 18$ sample, the maximum peak occured only at $350^{\circ} \mathrm{C}$ but the shoulder remained at the same temperature to the other. These modifications are the consequences of the functionalization process.

In table 1 are presented the weight losses from 100 to $900^{\circ} \mathrm{C}$ obtained for $\mathrm{Cl} 20 \mathrm{~A}, \mathrm{Cl} 20 \mathrm{~A}$ in $\mathrm{DCM}$ and $\mathrm{Cl} 20 \mathrm{~A}$ silylated samples. The total amount of the silane grafted onto clay edges was calculated taking into account the total mass losses from 100 to $900^{\circ} \mathrm{C}$ adjusted with that of $\mathrm{Cl} 20 \mathrm{~A}$ washed in DCM. We supposed that the same amount of quaternary ammonium salts get lost for all the samples. The best candidates for the functionalization are $\mathrm{Cl}$ 20A-Me and $\mathrm{Cl} 20 \mathrm{~A}-\mathrm{Ph}$. The amount of the silane grafted decreased with the increase of length of alkyl chain, respectively Cl 20A-C18.

Figure 2 presents XRD patterns of $\mathrm{Cl} 20 \mathrm{~A}, \mathrm{Cl}$ 20A-DCM and silane-modified $\mathrm{Cl} 20 \mathrm{~A}$. Cloisite 20A presents a strong peak at $3.45^{\circ}$ specific to the basal spacing $\left(\mathrm{d}_{001}\right)$ and three small peaks at $7.08^{\circ}, 19.9^{\circ}$ and $24.5^{\circ}$ specific to the crystalline structure.

Table 1. The weight losses obtained in the range 100 to $900^{\circ} \mathrm{C}$ for $\mathrm{Cl} 20 \mathrm{~A}, \mathrm{Cl} 20 \mathrm{~A}$ in $\mathrm{DCM}$ and $\mathrm{Cl} 20 \mathrm{~A}$ silylated samples.

\begin{tabular}{lccccc}
\hline Cloisite type & Cl 20A & Cl 20A-DCM & Cl 20A-Me & Cl 20A-Ph & Cl 20A-C18 \\
\hline $\mathrm{W}=$ weight loss between 100 and $900^{\circ} \mathrm{C}(\%)$ & 53.18 & 37.97 & 54.45 & 55.16 & 44.59 \\
$\mathrm{~W}_{0}=\mathrm{W}_{\mathrm{Cl} 20 \mathrm{~A}-\mathrm{R}-\mathrm{W}_{\mathrm{Cl} 20 \mathrm{~A}-\mathrm{DCM}}(\%)}$ & 15.21 & 0 & 16.48 & 17.19 & 6.62 \\
$\mathrm{R}=\mathrm{Me}, \mathrm{Ph}, \mathrm{C} 18$ & & & & & \\
\hline
\end{tabular}




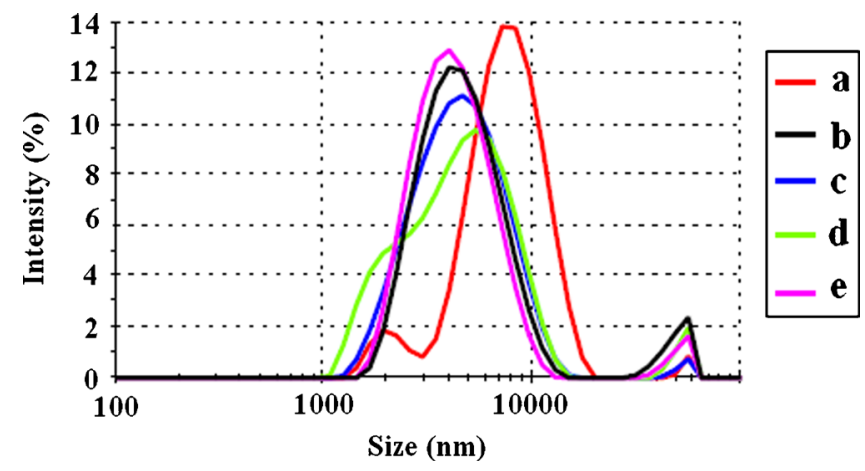

Figure 3. Size distributions obtained for Cloisite 20A derivatives dispersed in DCM (a, Cl 20A; b, Cl20A-DCM; c, Cl 20AMe; d, Cl 20APh; e, Cl 20AC18).

For $\mathrm{Cl} 20 \mathrm{~A}-\mathrm{DCM}$ and the silylated samples, a slight reduction in the basal spacing $\left(3.84^{\circ}\right)$ was observed compared with $\mathrm{Cl} 20 \mathrm{~A}$ due the washing of ammonium ions. Also, the modification of peak intensity and shape of all functionalized samples suggested that the silylation process affected to a certain degree the structure of $\mathrm{Cl} 20 \mathrm{~A}$. The appearance of a shoulder at $2.54^{\circ}$ only for the silylated samples could imply the intercalation with organic molecules. Therefore, the functionalization could be extended not only to edge covalent bonding but also to the modification in-between the clay layers or to a possible restructuring of the tactoids..$^{23,24}$

DLS analyses of the samples dispersed in $\mathrm{CH}_{2} \mathrm{Cl}_{2}$, showed the existence of two particles generation that corresponds to clay aggregate layers. For $\mathrm{Cl} 20 \mathrm{~A}$, the mean peak diameter was to be found around $800 \mathrm{~nm}$ with a shoulder at $200 \mathrm{~nm}$ and the second peak around $5400 \mathrm{~nm}$. For Cl 20A washed in DCM, the mean peak was positioned around $475 \mathrm{~nm}$ due to the loss of ammonium salts that influenced the clay dispersion capacity and consequently the average aggregates diameter of all silylatedsamples (figure 3).

The mean peak diameter decreased in the order Me-Ph-C18 and no significant modifications appeared

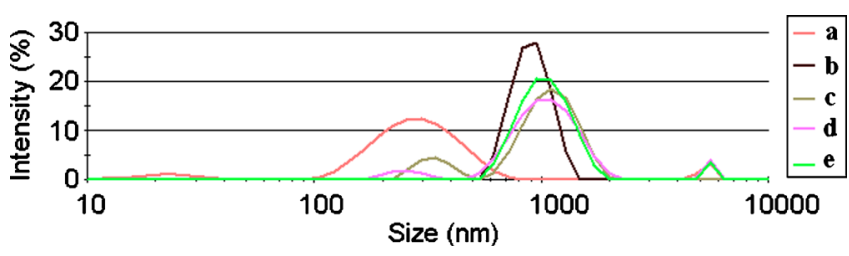

Figure 5. Size distributions obtained for $\mathrm{P}(\mathrm{VBTAC})$ and P(VBTAC)-clay (a, P(VBTAC); b, P(VBTAC)-Cl20A; c, P(VBTAC)-Cl20AMe; d, P(VBTAC)-Cl20APh; e, P(VBTAC)-Cl20AC18).

against $\mathrm{Cl}$ 20A-DCM. Cl 20A-Ph presented a small shoulder resembling to $\mathrm{Cl} 20 \mathrm{~A}$. It is almost impossible to discern between several factors such as: the influence of the loss of ammonium ions, the grafting degree, and the lengths of hydrocarbon chain and the nature of alkyl chain.

The dispersability of commercial and synthesized clays was observed by measuring the static contact angles of water (spreading of water as reference liquid onto clay mineral disk). ${ }^{10}$ It is well-known that clay minerals posses' amphiphilic behaviour, the contact angle lies between $0^{\circ}$ (hydrophilic) and $180^{\circ}$ (hydrophobic). The ratio hydrophilic/hydrophobic can be changed depending on the entrance of cations of different sizes and charges into the interlayer space. ${ }^{23}$ As shown in figure 4 , the contact angle of water obtained for the functionalized samples increased in comparison with commercial clay. Even if the contact angle for $\mathrm{Cl}$ 20A-DCM differed from $\mathrm{Cl} 20 \mathrm{~A}$ with $4^{\circ}$ (possible as a consequence of the loss of organo-modifier and the reorganization of the tactoids, as proved by XRD analyses), an increase of contact angle was determined for all silylated samples. This phenomenon clearly showed that the clays were hydrophobically modified through sol-gel processes. The best hydrophobic behaviour was obtained for $\mathrm{Ph}$ and $\mathrm{Me}$ derivatives (an increase of almost $20^{\circ}$ against $\mathrm{Cl} 20 \mathrm{~A}$ ) these results are in good agreement with TGA analyses.
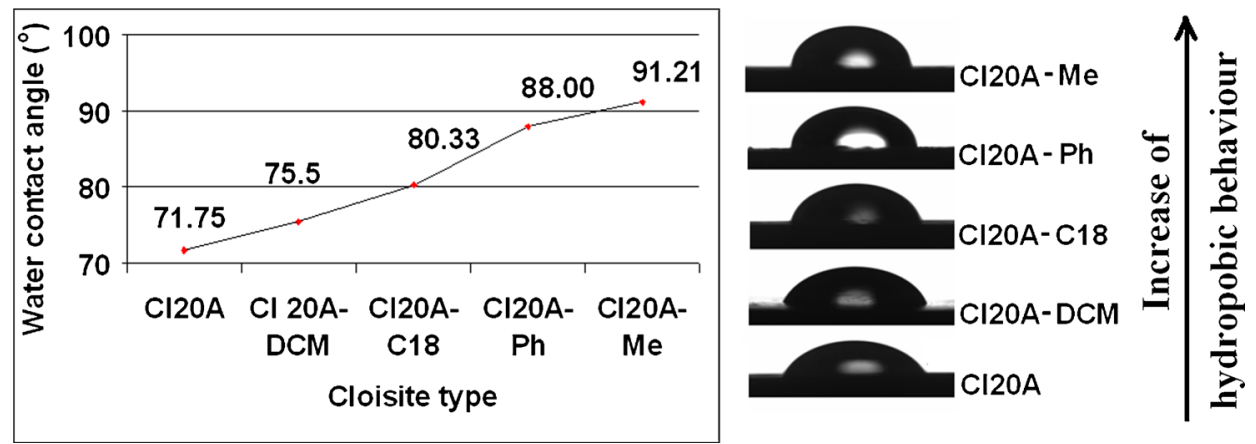

Figure 4. Water contact angles for Cloisite 20A derivatives. 
Table 2. DLS analyses for $\mathrm{P}(\mathrm{VBTAC})$ and $\mathrm{P}(\mathrm{VBTAC})$-clay.

\begin{tabular}{lccc}
\hline Sample & $\mathrm{d}_{\text {mean }}$ peak $(\mathrm{nm})$ & $\mathrm{Z}_{\text {Ave }}(\mathrm{nm})$ & Zeta potential $(\mathrm{mV})$ \\
\hline P(VBTAC) & 300 & 291 & 42 \\
P(VBTAC)-Cl 20A & 1000 & 2300 & 66.8 \\
P(VBTAC)-Me & 950 & 1457 & 68.6 \\
P(VBTAC)-Ph & 1000 & 1389 & 68.8 \\
P(VBTAC)-C18 & 1060 & 1478 & 67.7 \\
\hline
\end{tabular}

\subsection{Solution polymerization}

DLS analyses of the polymer diluted sample showed the presence of three particle generation corresponding to polymer micelle aggregates at $43 \mathrm{~nm}, 300 \mathrm{~nm}$ and $5600 \mathrm{~nm}$ (figure 5). Interestingly, for $\mathrm{Cl} 20 \mathrm{~A}$ only one particle generation was observed with the mean peak diameter at $1000 \mathrm{~nm}$ and a ZAverage of $2300 \mathrm{~nm}$ (table 2). This phenomenon is a consequence of the formation of polymer-clay aggregates. It is very possible that the cationic ammonium group from the polymer to be absorbed on the surface of the hydrophilic clay. Different from Cl 20A, Cl 20A silylated samples presented a more flattened mean peak and also a pronounced decreased value of ZAverage (around $1400 \mathrm{~nm}$ ). This is because of the interactions between hydrophilic polymer and modified clays; the presence of silane chain at the edge of the silicate layers affects the aggregation process. The zeta potential values are positive due to the cationic polymer and increased when adding layered silicates. The montmorillonite layers are negative charged because of the isomorphic substitution. The negative ions are balanced by charged balancing cations, in this case the quaternary ammonium salts which increase the zeta potential of polymer-clay solutions with $\sim 25 \mathrm{mV}^{22}$ (table 2).

FTIR spectra (figure 6) of the samples showed the corresponding peaks of polystyrene such as: $\mathrm{CH}$ stretches $\left(2850-3300 \mathrm{~cm}^{-1}\right), \mathrm{C}=\mathrm{C}$ stretches $(1610$ $1680 \mathrm{~cm}^{-1} ; 1400-1500 \mathrm{~cm}^{-1}$ ), as well as the ammonium salts peaks asymmetric NH stretching at 3000$3300 \mathrm{~cm}^{-1}$ and $\mathrm{CH}_{2}$ asymmetric stretching vibration at $2850-2940 \mathrm{~cm}^{-1}$. The composites samples presented the characteristic peaks of the clays at $1045 \mathrm{~cm}^{-1} \mathrm{Si}-\mathrm{O}$ stretching and $455 \mathrm{~cm}^{-1}$ and $517 \mathrm{~cm}^{-1}$ corresponding to $\mathrm{Si}-\mathrm{O}-\mathrm{Si}$ and $\mathrm{Al}-\mathrm{O}-\mathrm{Si}$ deformation, respectively. ${ }^{24}$ These results confirmed the inclusion of clay in the polymer matrix as observed in other studies. ${ }^{5,10,21}$

The XRD patterns of polymer and polymer-clay composites are shown in figure 7 . The d-spacing, which
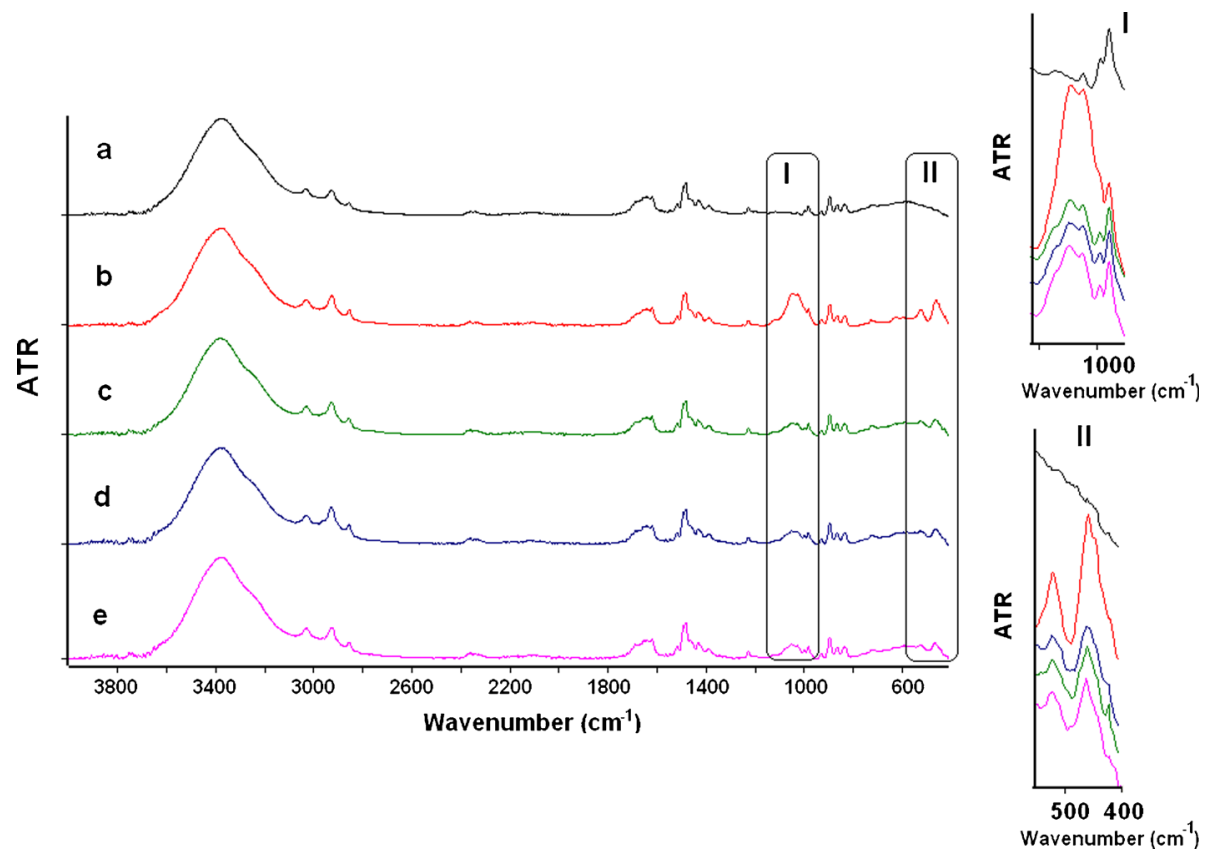

Figure 6. FTIR spectra obtained for $\mathrm{P}(\mathrm{VBTAC})$ and $\mathrm{P}(\mathrm{VBTAC})$ - clay composites (a, P(VBTAC); b, P(VBTAC)-Cl20A; c, P(VBTAC)-Cl20AMe; d, P(VBTAC)-Cl20APh; e, P(VBTAC)-Cl20AC18). 


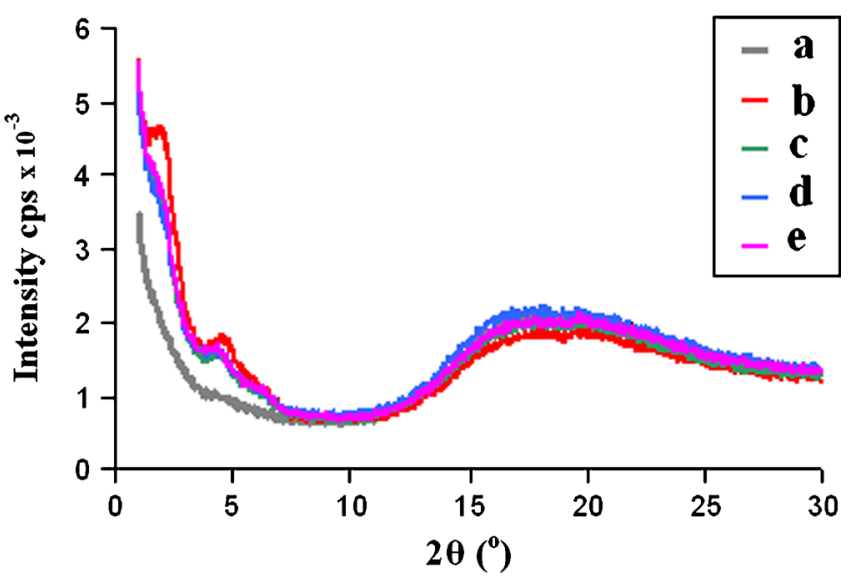

Figure 7. $\mathrm{X}$-Ray diffractograms obtained for $\mathrm{P}(\mathrm{VBTAC})$ and $\mathrm{P}(\mathrm{VBTAC})$-clay composites (a, $\mathrm{P}(\mathrm{VBTAC}) ; \mathrm{b}, \mathrm{P}(\mathrm{VB}$ TAC)-Cl20A; c, P(VBTAC)-Cl20AMe; d, P(VBTAC)-Cl 20APh; e, P(VBTAC)-Cl20AC18).

is the distance of clay galleries, shifted to lower two theta angles for polymer-clay samples (table 3). This phenomenon denoted the expansion of clay galleries ${ }^{25}$ despite volume contraction appeared as a result of radical polymerization. It was observed that the difference was larger in the case of the polymer-silylated samples than polymer-Cl $20 \mathrm{~A}\left(1.8^{\circ}\right.$ compared with $1.39^{\circ}$ and $2.6^{\circ}$ against $\left.1.5^{\circ}\right)$. The hydrophobic part of the amphilphilic polymer is compatible with the long chain quaternary ammonium salt between clay galleries and it is possible that a combined effect with hydrophobic silane chains from the edge, to promote an orientation of the polymer between silicate layers. Moreover, the XRD peaks of the silylated samples are broadening indicating a loss of parallel registry and reduction in tactoid size of clay, as observed by other researchers. ${ }^{26,27}$

Thermal behaviour of the obtained samples was checked by TGA analyses (figure 8 ). It was observed an increase of thermal stability in the presence of the clay. An important growth of final residue from $5.47 \mathrm{wt} \%$ up to $10-12 \mathrm{wt} \%$ indicated the presence of the clay in the polymer matrix. The maximum decomposing temperature corresponding to the maximum weight loss is considered a parameter for the estimation of thermal stability. The maximum decomposing temperatures obtained from the differential curves of TGA (DTG)

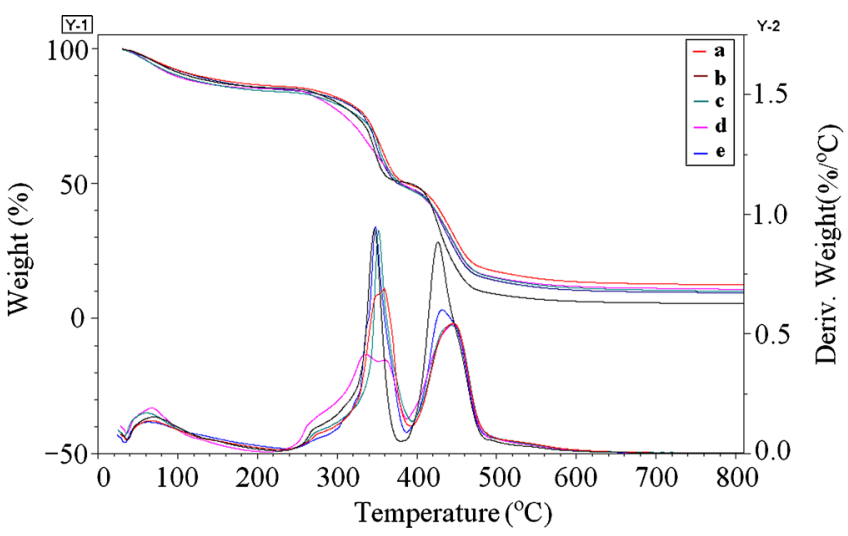

Figure 8. TGA-DTG curves obtained for $\mathrm{P}(\mathrm{VBTAC})$ and $\mathrm{P}(\mathrm{VBTAC})$-clay composites (a, P(VBTAC); b, P(VBTAC)Cl20A; c, P(VBTAC)-Cl20AMe; d, P(VBTAC)-Cl20APh; e, $\mathrm{P}(\mathrm{VBTAC})-\mathrm{Cl} 20 \mathrm{AC} 18)$.

are collected in table 4 . An increase of about $10^{\circ} \mathrm{C}$ for $\mathrm{T}_{\max 1}$ and $20^{\circ} \mathrm{C}$ for $\mathrm{T}_{\max 2}$ was registered for the polymer-clay samples compared with the neat polymer, clay layers acting as a barrier in the diffusion process. ${ }^{12}$

Interestingly, the maximum decomposing temperatures obtained for the silylated samples were below of Cl 20A temperatures, possibly due to the aggregation phenomena of the modified clay layers that led to a non-homogenous composite sample and consequently to a lower thermal stability. It should be noted that $\mathrm{T}_{\max 1}$ and $\mathrm{T}_{\max 2}$ increased as follows: $\mathrm{C} 18<\mathrm{Me}<\mathrm{Ph}$, the data are in good agreement with the TGA of the silylated samples. The order was the same as for the functionalized silane amount; therefore, the functionalization process influenced the thermal behaviour of the polymer-silylated clay composites.

The wettability of the polymer-clay films was estimated in order to obtain additional information regarding the interaction of the organoclays used in this work with the polymer at the solid-air surface. The contact angle data and the surface energies obtained, described average superficial properties of the material at the macroscale.

The total surface energy of the solid materials could be described as composed from the Lifshitz-van der Waals $\left(\gamma_{\mathrm{LW}}\right)$ surface energy (non-polar component) and the two polar components, the acid-base contributions

Table 3. Two theta angle values for P(VBTAC) and P(VBTAC)-clay.

\begin{tabular}{lccc}
\hline Clay type & $2 \theta\left(^{\circ}\right)$ & Polymer-clay & $2 \theta\left(^{\circ}\right)$ \\
\hline Cl 20A & $3.45 ; 7.08$ & P(VBTAC)-Cl 20A & $2.06 ; 4.74$ \\
Cl 20A-Me & $3.72 ; 7.34$ & P(VBTAC)-Me & $1.98 ; 4.4$ \\
Cl 20A-Ph & $3.68 ; 7.18$ & (VBTAC)-Ph & $1.92 ; 4.4$ \\
Cl 20A-C18 & $3.6 ; 6.68$ & P(VBTAC)-C18 & $1.9 ; 4.4$ \\
\hline
\end{tabular}


Table 4. The maximum decomposing temperatures and the residue obtained at $800^{\circ} \mathrm{C}$ for $\mathrm{P}(\mathrm{VBTAC})$ and $\mathrm{P}(\mathrm{VBTAC})$-clay.

\begin{tabular}{lccc}
\hline Polymer-clay & $\mathrm{T}_{1 \max }\left({ }^{\circ} \mathrm{C}\right)$ & $\mathrm{T}_{2 \max }\left({ }^{\circ} \mathrm{C}\right)$ & Residue at $800{ }^{\circ} \mathrm{C}$ \\
\hline $\mathrm{P}($ VBTAC $)$ & 346.7 & 426.33 & 5.47 \\
$\mathrm{P}($ VBTAC)-Cl 20A & 358.1 & 446.39 & 12.44 \\
$\mathrm{P}($ VBTAC)-Me & 352.38 & 442.29 & 10.09 \\
$\mathrm{P}($ VBTAC)-Ph & $335 / 360$ & 345.13 & 10.81 \\
$\mathrm{P}($ VBTAC $)-\mathrm{C} 18$ & 349.27 & 431.26 & 9.54 \\
\hline
\end{tabular}

that indicate the surface character as electron acceptor or respective, donor. The polar components are denoted as $\gamma^{+}$and and $\gamma^{-}$, the Lewis acid parameter and the Lewis base parameter, respectively.

The surface energy components of the claypolymeric films are shown in table 5 .

As it was expected, the pristine poly(VBTAC) film exhibited the highest polar component, with the more basic due to the presence of the ammonium groups in the macromolecular chain. The presence of Cloisite 20 A clay in the polymeric film resulted in an increase in the dispersion component and a reduction of the basic contribution of the polar component. Further functionalization of the clay with various organic derivatives (methyl, phenyl and ocatdecyl) led to similar modification of the polarity of the hybrid films. The highest influence was expected for the Cloisite 20A modified with long hydrocharbon chains, but the values obtained for the dispersive component of the surface free energy was not significantly higher than those for the other organo-clays. This result was in accordance with the thermogravimetic data, indicating that a very small amount of Cloisite was functionalized, with a reduced influence of the organo-clay in the behaviour of the hybrid film.

The functionalized clays influenced the surface properties of the hybrid poly(VBTAC) films. The variation of the dispersive component of the surface free energy does not correlate with the hydrophobicity of the organic moieties in the modified clays due to the different functionalization degree and to the different distribution of the aggregated and not aggregated nanoclays in the polymeric matrix.

\section{Conclusion}

A commercial clay-Cl $20 \mathrm{~A}$ was organo-modified to an advanced material by edge covalent bonding with different types of monofunctional alkoxysilanes. TGA analyses confirmed a greater organic amount induced by the grafted silane, which decreased with the increase of length of alkyl chain. The modifications in peak shape and intensity of XRD patterns of all functionalized clays suggested that the silylation process affected to a certain degree the structure of $\mathrm{Cl} 20 \mathrm{~A}$. The clays were hydrophobically modified through sol-gel processes as observed by contact angle measurements of the modified clay, the best hydrophobic behaviour was obtained for $\mathrm{Ph}$ and $\mathrm{Me}$ derivatives (an increase of almost $20^{\circ}$ against $\mathrm{Cl} 20 \mathrm{~A}$ ).

Polystyrene hybrid solutions were prepared in the presence of several types of modified clays. For the dispersed systems obtained with modified clays, it was observed that particle average sizes increased for polymer-layered silicate latexes in comparison with those obtained for blank solution. FTIR, XRD and TGA results confirmed the inclusion of clay in the polymer matrix. Mainly, intercalated composites were obtained. An increase of thermal stability of polymer-clay samples compared with the neat polymer was observed, and clay layers were acting as a barrier in the diffusion

Table 5. The surface energy components $\left(\mathrm{mJ} \mathrm{m}^{-2}\right)$ of hybrid polymer P(VBTAC)-clay films computed according to Lifshitz - van der Waals theory.

\begin{tabular}{lcccr}
\hline Sample & $\begin{array}{c}\gamma_{\mathrm{s}} \\
\left(\mathrm{mJ} \mathrm{m}^{-2}\right)\end{array}$ & $\begin{array}{c}\gamma_{s}^{L W} \\
\left(\mathrm{~mJ} \mathrm{~m}^{-2}\right)\end{array}$ & $\begin{array}{c}\gamma_{s}^{+} \\
\left(\mathrm{mJ} \mathrm{m}^{-2}\right)\end{array}$ & $\begin{array}{c}\gamma_{s}^{-} \\
\left(\mathrm{mJ} \mathrm{m}^{-2}\right)\end{array}$ \\
\hline P(VBTAC) & 45.56 & 31.64 & 2.11 & 22.95 \\
P(VBTAC)-Cl 20A & 47.83 & 41.63 & 0.79 & 12.18 \\
P(VBTAC)-Me & 44.25 & 40.79 & 0.80 & 16.56 \\
P(VBTAC)-Ph & 44.36 & 40.98 & 0.21 & 13.78 \\
P(VBTAC)-C18 & 43.22 & 40.79 & 0.36 & 16.32 \\
\hline
\end{tabular}


process. The wettability data showed the reduction of the hydrophilic character of the poly(VBTAC) film in the presence of the organo-modified clays. The functionalization of Cloisite 20A led to an increase of the dispersive component and a decrease of the Lewis-base component.

\section{Acknowledgements}

This work was supported by a grant from the Romanian National Authority for Scientific Research, CNDIUEFISCDI, project number 3.2-1391.

\section{References}

1. Sokolova T A, Yu E, Pakhomova and Zaidelman F R 2012 Moscow Univ. Soil Sci. Bull. 67143

2. Anirudhan T S, Sandeep S and Divya P L 2012 RSC Adv. 29555

3. Cui H W and Du G B 2011 J. Chem. Eng. Mat. Sci. 2 122

4. Ianchis R, Corobea M C, Donescu D, Rosca I D, Cinteza L O, Nistor L C, Vasile E, Marin A and Preda S 2012 J. Nanopart. Res. 141233

5. Patel H A, Somani R S, Bajaj H C and Jasra R V 2006 Bull. Mater. Sci. 29133

6. Sirapanichart S, Monvisade P, Siriphannon P and Nukeaw J 2011 Iranian Polym. J. 20803

7. Velde B 1992 Introduction to clay minerals (London, New York: Chapman and Hall)

8. Xu Y, Qinhui C, Weibin B and Lin J 2012 Polym. Bull. 68983

9. Choudhury T and Misra N M 2010 Bull. Mater. Sci. 33 165
10. Ianchis R, Cinteza L O, Donescu D, Petcu C, Corobea M C, Ghiurea M, Somoghi R and Spataru C 2011 Appl. Clay Sci. 5296

11. Tong Z and Deng Y 2007 Polymer 484337

12. De Maria A, Aurora A, Montone A, Tapfer L, Pesce E, Balboni R, Schwarz M and Borriello C 2012 J. Nanopart. Res. 136049

13. Bitinis N, Hernandez M, Verdejo R, Kenny J M and Lopez-Manchado M A 2011 Adv. Mater. 235229

14. Jaeger W, Bohrisch J and Laschewsky A 2010 Prog. Polym. Sci. 35511

15. Lee Y S and Byoun Y S 2002 Bull. Korean Chem. Soc. 231833

16. Kumar V, Bhardwaj Y K, Sabharwal S and Mohan H 2003 J. Radiat. Res. 44161

17. Donescu D, Somoghi R, Ghiurea M, Ianchis R, Petcu C, Gavriliu S, Lungu M, Groza C, Ionescu R C and Panzaru C 2013 J. Chem. Sci. 125419

18. Meneghetti P and Qutubuddin S 2006 Thermochim. Acta 44274

19. Van Oss C J, Chaudhury M K and Good R J 1988 Chem. Rev. 88927

20. Marras S I, Tsimpliaraki A, Zuburtikudis I and Panayiotou C 2007 J. Coll. Interf. Sci. 315520

21. Qian Z, Zhou H, Xu X, Ding Y, Zhang S and Yang M 2009 Polym. Compos. 301234

22. Zhang J, Gupta R K and Wilkie C A 2006 Polymer 47 4537

23. Koseva S, Brezovska S, Bosevska V and Burevski D J 2003 Serb. Chem. Soc. 68629

24. Nayak P S and Singh B K 2007 Bull. Mater. Sci. 30235

25. Mansoori Y, Roojaei K, Zamanloo M R and Imanzadeh G 2012 Bull. Mater. Sci. 351063

26. Akbarinezhad E, Ebrahimi M, Sharif F, Attar M M and Faridi H R 2011 Prog. Org. Coatings 7039

27. Potarniche C G, Vuluga Z, Donescu D, Christiansen J C, Eugeniu V, Radovici C, Serban S, Ghiurea M, Somoghi $\mathrm{R}$ and Beckmann S 2011 Surf. Interface. Anal. doi: 10. 1002/sia. 3797 